\title{
Neopolystoma fentoni n. sp. (Monogenea: Polystomatidae) a Parasite of the Conjunctival Sac of Freshwater Turtles in Costa Rica
}

\author{
Thomas R Platt \\ Department of Biology, Saint Mary's College, Notre Dame, IN 46556, USA
}

Neopolystoma fentoni $\mathrm{n}$. sp. is described from the conjunctival sac of Kinosternon leucostomum (Duméril, Bibron, and Duméril 1851) and Rhinoclemmys pulcherrima (Gray 1855) from the Guanacaste Conservation Area in Costa Rica. The new species differs from all other species of Neopolystoma, except $N$. elizabethae Platt 2000 in possessing a circle of eight genital spines that are recurved and possess a crescent-shaped base. $N$. fentoni $\mathrm{n}$. sp. differs from $N$. elizabethae in lacking cecal diverticula and in a number of morphometric criteria.

Key words: Monogenea - freshwater turtle parasite - Neopolystoma - conjunctival sac - Costa Rica

The monogene family Polystomatidae contains three genera parasitic exclusively in turtles. The majority of species of polystomatids described from turtles inhabit either the oral cavity or the urinary bladder as adults (du Preez \& Lim 2000). A small number of species have been reported from the conjunctival sacs of freshwater turtles (Platt 2000). Examination of specimens of two species of turtles, Kinosternon leucostomum (Duméril, Bibron, and Duméril 1851) and Rhinoclemmys pulcherrima (Gray 1855), from the Guanacaste Conservation Area, Costa Rica, yielded specimens of Neopolystoma from the conjunctival sac that are herein described as a new species.

\section{MATERIALS AND METHODS}

Turtles were collected by hand from permanent pools in dry stream beds in the vicinity of the operations center of the Guanacaste Conservation Area during June 1998. Turtles were returned to the laboratory and examined within $48 \mathrm{~h}$ of capture. The animals were decapitated and necropsies were conducted following standard procedures. The lower eyelids were resected and worms were removed from the conjunctival sac with fine forceps and a camel hair brush.

Worms were killed, without flattening, in hot (steaming) 5\% formalin. Specimens were placed in a vial with enough saline to cover them. Hot formalin was added to the vial, the vial; was quickly

Financial support: Saint Mary's College research grant Fax: 219-284-4716. E-mail: tplatt@ saintmarys.edu Received 7 January 2000

Accepted 24 May 2000 capped and gently shaken. The worms were stored in the same medium, stained in Mayer's haematoxylin (Pritchard \& Kruse 1982), following standard procedures, and mounted in Canada balsam for examination as whole mounts. Definitions of prevalence and mean intensity follow the usage of Bush et al. (1997).

Specimens were observed with a Nikon Optiphot light microscope using bright field and phase contrast illumination. Drawings were made with the aid of a camera lucida and measurements were made using an ocular micrometer. All measurements are in micrometers with the mean followed by the range in parentheses, and $\mathrm{n}$ refers to the number of specimens measured.

\section{DESCRIPTION}

Neopolystoma fentoni $\mathrm{n}$. sp.

Morphometrics: based on ten specimens (Figs 1-3; Table I)

With the characteristics of the genus. Body pyriform, maximum width near midbody (Fig. 1). Tegument aspinose. Haptor slightly wider than long; six type 2 haptoral suckers (Pichelin 1995). Marginal hooks 16, $12.5(11.8-12.7 ; \mathrm{n}=4)$ with blade oriented toward haptoral margin; hook pairs VI-VIII between anterior pair of suckers; hook pairs III-V in base of each sucker; hook pairs I-II between posterior-most pair of suckers. Marginal hooks rarely present, however, hoods typically present. Oral sucker large, wider than long. Pharynx large, wider than long; PW/OSW $=0.81: 1$. Genital bulb (Fig. 2) round to slightly oval; genital spines 8 , recurved from base to tip with crescentshaped handle at right angle to blade; eight genital spines 11 long $(n=8)$. Seminal vesicle small, oval. Testis located near midbody (excluding haptor). 
Genital system exhibits situs inversus. Ovary oval, anterior to testis. Genito-intestinal canal present. Uterus conspicuous, elliptical; ova elliptical. Vaginae lateral, uncapped, in second $1 / 4$ of body. Vaginae from anterior end/total length as a percent $=39.97$ (37.5-44.3). Vitellarium follicular from level of genital pore to anterior margin of haptor, filling intercecal space not occupied by genital structures; not extending into penduncle.

Taxonomic summary

Type host: Kinosternon leucostomum (Duméril, Bibron, and Duméril 1851): Kinosternidae Other known host: Rhinoclemmys pulcherrima (Gray 1855): Bataguridae

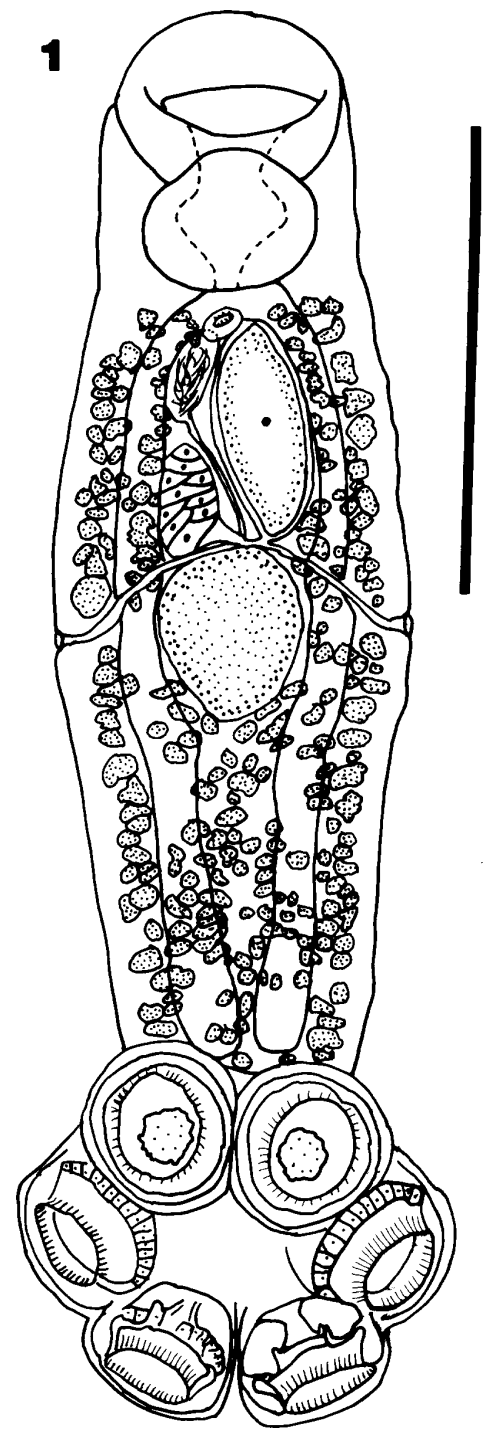

Site of infection: conjunctival sac

Type locality: Quebrada Costa Rica (10 $0^{\circ} 49.666^{\prime}$ $\mathrm{N}, 85^{\circ} 38.216 \mathrm{~W}$ ), Guanacaste Conservation Area, Santa Rosa, Guanacaste, Costa Rica

Other known localities: Quebrada el Duende $\left(10^{\circ}\right.$ $\left.50.236^{\prime} \mathrm{N}, 85^{\circ} 36.724^{\prime} \mathrm{W}\right)$ and San Gerardo $\left(10^{\circ}\right.$ $52.55^{\prime} \mathrm{N}, 85^{\circ} 23.27^{\prime} \mathrm{W}$ ), Guanacaste Conservation Area, Santa Rosa, Guanacaste, Costa Rica.

Type material: holotype and four paratypes: United States National Parasitological Collection, holotype (collection no. 89943); four paratypes (nos 899446): four paratypes Helminthological Collection of the Oswaldo Cruz Institute (collection nos 34292, 34293a-b, 34294).

Etymology: this species is named in memory of

Neopolystoma fentoni n. sp. in ventral view. Fig. 1: whole mount, ventral (holotype), bar $=500$. Fig. 2: genital bulb and genital spines, ventral (paratype), bar $=50$. Fig. 3: genital spines, ventral (paratype), bar $=20$. Fig. 4: marginal spine, ventral (paratype), bar $=20$. 
my father-in-law, Mr William S Fenton, as a tribute to his friendship and counsel over the last quarter century.

\section{REMARKS}

The family Polystomatidae contains three genera that exclusively parasitize turtles. The genus Neopolystoma Price, 1939 is differentiated from Polystomoides Ward, 1917 and Polystomoidella Price, 1939, by the absence of anchors between the posterior-most pair of suckers on the haptor. The new species clearly belongs to the genus Neopolystoma. Specimens collected from $K$. leucostomum and R. pulcherrima overlapped morphometrically in all attributes and are treated as a single species, N. fentoni, which is considered new to science. Prevalence and intensity of $N$. fentoni were low in both host species (Table II).

Seven species of Neopolystoma have been described from the conjunctival sac of freshwater turtles (Table III). $N$. fentoni $\mathrm{n}$. sp. differs from all other species in the genus, except $N$. palpabrae Strelkov, 1950, and N. elizabethae Platt, 2000, in having genital spines with a crescent-shaped base. $N$. palpabrae was described by Strelkov (1950) from the soft-shelled turtle, Pelodiscus sinensis
(Wiegmann 1835), from Lake Chanka, north of Vladivostok, in the former Soviet Union. The genital spines in N. palpabrae are identical in shape to those of the new species; however, they numbered 16 and are arranged in a circle of alternating large and small spines. Strelkov (1950) did not give separate measurements for the large and small spines for $N$. palpabrae, however, the range of spine length was given as 10-16 $\mu \mathrm{m}$, while the lengths of the spines of $N$. fentoni and N. elizabethae are 11 and 10 , respectively.

\section{TABLE II}

Prevalence and mean intensity of Neopolystoma fentoni $\mathrm{n}$. sp. in freshwater turtles from the Guanacaste Conservation Area, Santa Rosa, Costa Rica

\begin{tabular}{lcc}
\hline Host & $\%$ prevalence & $\begin{array}{c}\text { X intensity } \\
\text { (range) }\end{array}$ \\
\hline Kinosternon leucostomum & $12.5(2 / 16)$ & $2.0(1-3)$ \\
Rhinoclemmys pulcherrima & $28.6(2 / 7)$ & $3.5(3-4)$ \\
\hline
\end{tabular}

Number infected/number examined; total number of parasites/number of hosts infected

\section{TABLE I}

Morphometric comparison of Neopolystoma fentoni $\mathrm{n}$. sp. and Neopolystoma elizabethae Platt, 2000 (mean followed by the range in parentheses)

\begin{tabular}{llll}
\hline Character & & $N$. fentoni $(\mathrm{n}=10)$ & N. elizabethae $(\mathrm{n}=4)$ \\
\hline Body & $\mathrm{L}$ & $1985(1500-2450)$ & $3125(2550-3675)$ \\
& $\mathrm{W}$ & $568(426-760)$ & $823(640-990)$ \\
Haptor & $\mathrm{L}$ & $571(449-690)$ & $865(790-970)$ \\
& $\mathrm{W}$ & $683(550-850)$ & $975(880-1070)$ \\
Marginal hooks $(\mathrm{n}=4 ; 8)$ & $\mathrm{L}$ & $12.5(11.8-12.7)$ & $12.3(11.8-12.7)$ \\
Haptor sucker $(\mathrm{n}=60 ; 24)$ & $\mathrm{D}$ & $265(210-326)$ & $372(344-408)$ \\
Oral sucker & $\mathrm{L}$ & $230(150-303)$ & $271(251-292)$ \\
& $\mathrm{W}$ & $370(240-496)$ & $473(449-540)$ \\
Pharynx & $\mathrm{L}$ & $216(156-257)$ & $255(216-268)$ \\
& $\mathrm{W}$ & $278(185-367)$ & $305(268-320)$ \\
Ph/OS & & $0.82: 1(0.75-0.93: 1)$ & $0.65: 1(0.61-0.71)$ \\
Genital bulb & $\mathrm{L}$ & $55(43-70)$ & $58(50-63)$ \\
& $\mathrm{W}$ & $60(30-83)$ & $57(45-63)$ \\
Seminal vesicle & $\mathrm{L}$ & $79(50-100)$ & $151(140-175)$ \\
& $\mathrm{W}$ & $50(35-65)$ & $63(50-68)$ \\
Testis & $\mathrm{L}$ & $225(98-367)$ & $208(178-262)$ \\
& $\mathrm{W}$ & $181(78-251)$ & $155(140-192)$ \\
Ovary & $\mathrm{L}$ & $103(80-245)$ & $301(218-350)$ \\
& $\mathrm{W}$ & $105(55-169)$ & $122(100-146)$ \\
Ova $(\mathrm{n}=7 ; 3)$ & $\mathrm{L}$ & $286(245-332)$ & $348(332-367)$ \\
Vaginae to anterior end & $\mathrm{W}$ & $136(122-146)$ & $120(117-122)$ \\
VAE/TL $(\%)$ & & $788(510-920)$ & $1071(880-1250)$ \\
Uterus $(\mathrm{empty} ; \mathrm{n}=3)$ & $\mathrm{L}$ & $40.0(37.5-44.3)$ & $34.3(33.2-35.4)$ \\
& $\mathrm{W}$ & $99(50-133)$ & $330(188-402)$ \\
& & $35(33-38)$ & $151(140-192)$ \\
\hline
\end{tabular}

$\mathrm{Ph} / \mathrm{OS}$ : pharynx width-oral sucker width ratio; VAE/TL (\%): vaginae to anterior end as a percent of total length 
Pichelin (1995) described four species of Neopolystoma from the conjuntival sacs of freshwater turtles in Australia. Three species had 20 or more genital spines which would clearly separate them from the American forms. Only N. cribbi Pichelin, 1995 possesses a smaller number of genital spines (range 6-10), however, they possess typical fan-shaped roots (Pichelin 1995) and lack the crescent-shaped base present in $N$. fentoni and $N$. elizabethae. du Preez and Lim (2000) described $N$. liewi from the conjunctival sac of the batagurid turtle, Curora amboinensis, from Malaysia. This species also possesses a small number of genital spines (8-11); however, they also have typical "fanshaped" roots and lack the recurved base present in N. fentoni and N. elizabethae.

$N$. fentoni appears most closely related to $N$. elizabethae as the genital and marginal spines are nearly identical in shape and size; however, the new species differs from the North American form in lacking intestinal diverticula present in the posterior half of the cecae. The two forms also differ in number of morphometric criteria (Table I). $N$. fentoni is significantly smaller, the ratio of pharyngeal and oral suck width is greater, the diameter of the haptoral suckers is larger, the testis is larger, the seminal vesicle is smaller, and the eggs are, on average, 60 shorter. These differences are sufficient to warrant recognizing a new species.

The conjunctival sac has been overlooked as a site for the presence of polystomatids. The discovery of $N$. fentoni is only the seventh species recorded from this location since the first report of N. palpabrae from Pelodiscus (=Amyda) sinensis (Wiegmann, 1835) by Strelkov (1950). Pichelin (1995) described four species of Neopolystoma from the side-necked turtles (Chelidae) in Australia and Platt (2000) described N. elizabethae from the western painted turtle, Chrysemys picta belli
(Gray, 1831) from northern Michigan in the United States.

The range of turtle taxa harboring Neopolystoma spp. in the conjunctival sac is shown in Table III. In addition to the fact that species in both major lineages of extant turtles harbor these worms, the five host families represent nearly $70 \%$ of genera and species of living turtles (Iverson 1992). Nor are these parasites rare in the individual host populations examined. Strelkov (1950) reported a prevalence of 35\% for N. palpabrae, while Platt (2000) reported $80 \%$ prevalence for $N$. elizabethae in a very small sample $(\mathrm{n}=5)$. While published data are not available for the Australian polystomatids, the author found over $20 \%$ prevalence in a sample of 70 chelids in Australia (Platt, unpublished observations). Any parasitologist examining turtles should examine the conjunctival sac for polystomes.

Turtles and turtle helminths may provide a valuable, if overlooked, resource for the study of hostparasite coevolution, biogeographic analysis, and speciation. The distribution of polystomatids in Australian and southeast Asian turtles (Rohde \& Pearson 1980) and blood flukes (Family Spirorchiidae) (Platt 1992) suggest that these associations date to the breakup of Pangea ( 200 mya). Littlewood et al. (1997) demonstrated, using molecular techniques, that polystomatid species from the same location (e.g., urinary bladder) but geographically disjunct localities, are more closely related to each other than congeners from the same host but a different location (e.g., oral cavity). Turtle populations in the midwestern United States and Australia typically harbor polystomatids in the mouth, urinary bladder and conjunctival sac (Platt, unpublished observations). Therefore, these helminths offer the opportunity to provide three independent tests of coevolution-

\section{TABLE III}

Classification of extant turtle species (Order Testudines) known to harbor Neopolystoma spp. in the conjunctival sac (turtle classification based on various sources)

\begin{tabular}{|c|c|c|c|}
\hline Classification & & Locality & Author \\
\hline \multicolumn{4}{|l|}{ Infraorder Pleurodira } \\
\hline Family Chelidae & $\begin{array}{l}\text { Emydura spp. } \\
\text { Chelodina spp. } \\
\text { Elseya latisternum }\end{array}$ & Australia & Pichelin (1995) \\
\hline \multicolumn{4}{|l|}{ Infraorder Cryptodira } \\
\hline $\begin{array}{l}\text { Family Trionychidae } \\
\text { Family Kinosternidae } \\
\text { Family Emydidae } \\
\text { Family Bataguridae }\end{array}$ & $\begin{array}{l}\text { Pelodiscus sinensis } \\
\text { Kinosternon leucostomum } \\
\text { Chrysemys picta belli } \\
\text { Rhinoclemmys pulcherrima } \\
\text { Curora amboinensis }\end{array}$ & $\begin{array}{l}\text { Russia } \\
\text { Costa Rica } \\
\text { United States } \\
\text { Costa Rica } \\
\text { Malaysia } \\
\end{array}$ & $\begin{array}{l}\text { Strelkov (1950) } \\
\text { Current study } \\
\text { Platt (2000) } \\
\text { Current study } \\
\text { du Preez \& Lim (2000) }\end{array}$ \\
\hline
\end{tabular}


ary, biogeographic and speciation hypotheses if sufficient material is made available. South America and Asia are two areas of high turtle diversity, yet recent checklists of monogenes from these areas identify only four and seven species of polystomes reported in the literature, respectively (Kohn \& Cohen 1998, Lim 1998). Judicious examination of turtles for helminths from these areas, preserving specimens for both morphological and molecular analysis, has the potential to yield significant information about the history of life.

\section{ACKNOWLEDGMENTS}

To Dr Roger Blanco, Research Director at the conservation area, for the use of the facilities and his generous hospitality. To Dr Daniel R Brooks who arranged the trip and provided valuable assistance in the field. To Drs Anindo Choudhury and Derek Zelmer who provided companionship and assistance in collecting the turtles. To Ms Akmaral Omarova, Saint Mary's College, for assistance in translating the paper by Strelkov.

\section{REFERENCES}

Bush AO, Lafferty KD, Lotz, JM, Shostak AW 1997. Parasitology meets ecology on its own terms: Margolis et al. revisited. J Parasitol 83: 575-583.

du Preez, LH, Lim LHS 2000. Neopolystoma liewi sp.n. (Monogenea: Polystomatidae) from the eye of the Malayan box turtle (Curora amboinensis). Folia Parasitol 47: 11-16.

Iverson JB 1992. A Revised Checklist with Distribution Maps of the Turtles of the World, published by the author, Richmond, IN, 363 pp.
Kohn A, Cohen SC 1998. South American Monogenea - List of species, hosts and geographical distribution. Int J Parasitol 28: 1517-1554.

Lim LHS 1998. Diversity of monogeneans in Southeast Asia. Int J Parasitol 28: 1495-1515.

Littlewood DTJ, Rohde K, Clough KA 1997. Parasite speciation within or between host species? - Phylogenetic evidence from site-specific polystome monogeneans. Int J Parasitol 27: 1289-1297.

Pichelin S 1995. The taxonomy and biology of the Polystomatidae (Monogenea) in Australian freshwater turtles (Chelidae, Pleurodira). J Nat Hist 29: 1345-1381.

Platt TR 1992. A phylogenetic and biogeographic analysis of the genera of Spirorchinae (Digenea: Spirorchidae) parasitic in freshwater turtles. $J$ Parasitol 78: 616-629.

Platt TR 2000. Helminth parasites of the western painted turtle, Chyrsemys picta belli (Gray), including Neopolystoma elizabethae n. sp. (Monogenea: Polystomatidae), a parasite of the conjunctival sac. $J$ Parasitol 86: in press.

Pritchard MH, Kruse GOW 1982. The Collection and Preservation of Animal Parasites, Technical Bulletin No. 1, University of Nebraska Press, Lincoln, NE, 141 pp.

Rohde K, Pearson JC 1980. Two polystomes (Monogenea) from Australian river tortoises (Pleurodira, Chelidae), Polystomoides australensis sp. nov. from Emydura krefftii and Neopolystoma chelodinae (MacCallum, 1919) from Chelodina longicollis. Zool Anzgr 204: 191-208.

Strelkov YuA 1950. A new species of monogenetic trematode from Amyda sinensis. Dokl Akad Nauk SSSR 74: 159-162 (In Russian). 